\title{
Enhancing Properties of Aerospace Alloy Elektron 21 Using Boron Carbide Nanoparticles as Reinforcement
}

\author{
Sravya Tekumalla ${ }^{1}$,, $\mathrm{Ng}$ Joo Yuan ${ }^{1}$, Meysam Haghshenas ${ }^{2}$ and Manoj Gupta ${ }^{1, *(\mathbb{D}}$ \\ 1 Department of Mechanical Engineering, National University of Singapore, Singapore 117575, Singapore; \\ tvrlsravya@u.nus.edu (S.T.); e0004161@u.nus.edu (N.J.Y.) \\ 2 Department of Mechanical, Industrial and Manufacturing Engineering, University of Toledo, Toledo, \\ OH 43606, USA; Meysam.Haghshenas@UToledo.Edu \\ * Correspondence: mpegm@nus.edu.sg
}

Received: 12 September 2019; Accepted: 9 December 2019; Published: 12 December 2019

\section{Featured Application: Aerospace sector.}

\begin{abstract}
In this study, the effect of nano- $\mathrm{B}_{4} \mathrm{C}$ addition on the property profile of Elektron 21 (E21) alloys is investigated. E21 reinforced with different amounts of nano-size $\mathrm{B}_{4} \mathrm{C}$ particulates was synthesized using the disintegrated melt deposition technique followed by hot extrusion. Microstructural characterization of the developed E21- $\mathrm{B}_{4} \mathrm{C}$ composites revealed refined grains with the progressive addition of boron carbide nanoparticles. The evaluation of mechanical properties indicated a significant improvement in the yield strength of the nanocomposites under compressive loading. Further, the E21-2.5B $\mathrm{B}_{4} \mathrm{C}$ nanocomposites exhibited the best damping characteristics, highest young's modulus, and highest resistance to ignition, thus featuring all the characteristics of a material suitable for several aircraft applications besides the currently allowed seat frames. The superior mechanical properties of the $\mathrm{E} 21-\mathrm{B}_{4} \mathrm{C}$ nanocomposites are attributed to the refined grain sizes, uniform distribution of the nanoparticles, and the thermal insulating effects of nano- $\mathrm{B}_{4} \mathrm{C}$ particles.
\end{abstract}

Keywords: Elektron 21; boron carbide nanoparticles; nanocomposites; properties

\section{Introduction}

With globalization, modern transport has evolved to play an integral part of the global economy; with the net worth of the automotive industry at 2 trillion USD [1] and the aerospace industry at 2.7 trillion USD [2]. However, it is also a significant source of pollution with approximately $13 \mathrm{wt} . \%$ of overall greenhouse gas and $25 \mathrm{wt} . \%$ of $\mathrm{CO}_{2}$ emissions from the fossil fuel combustion [3]. The global aviation industry generates around $2 \mathrm{wt} . \%$ of all human-induced emissions and $12 \mathrm{wt} . \%$ of $\mathrm{CO}_{2}$ emissions from all transport sources. As the number of passengers traveling by air is projected to increase from 3 billion in 2012 to 16 billion in 2050 and the nitrogen oxide $\mathrm{NO}_{\mathrm{x}}$ emissions from burning jet fuel are expected to double before 2020, there is a concern about the detrimental effect on the environment. To reduce the negative impact, the Air Transport Action Group has set up several ambitious targets to become carbon neutral by 2020, while improving the fuel efficiency by $1.5 \mathrm{wt} . \%$ per year and halving carbon emissions by 2050 compared to 2005 levels [4]. In order to meet the environmental responsibilities, development of new structural materials for aerospace applications is driven by the need for light weight components in both cast and wrought forms. In this regard, Mg-based alloys and composites exhibit excellent specific strength and damping capacity with their very low density, and are promising materials for aerospace applications in view of light weighting the aircrafts. Over the recent years, passenger seats on-board airlines served to gain the most attention as they offer significant opportunities for weight reduction through usage of magnesium-based materials. 
Until 2015, there was a ban by the Federal Aviation Administration (FAA) in the use of magnesium in aviation due to safety concerns stemming from the ignition susceptibilities of magnesium. However, as of today, Elektron ${ }^{\circledR} 43$ (WE43) and Elektron ${ }^{\circledR} 21$ (E21) are the only magnesium alloys that have met the cited performance requirements by passing extensive flammability tests conducted by the FAA, including seven full-scale aircraft interior tests [5]. These alloys are heavily rare earth dominated with elements such as Neodymium, Gadolinium, and other elements such as Zinc and Zirconium. These added alloying elements either dissolve in the matrix or form secondary phases with $\mathrm{Mg}$, which play an extremely influential role in deciding the performance of the alloy [6,7]. With the above mentioned combination of elements, magnesium offers a combination of good castability, mechanical properties, and corrosion resistance and, hence, can be rendered useful in both civil and military aircraft and also in the automobile (motorsport) industry $[8,9]$. To extend their applications to other aircraft components apart from seat frames, such as gearbox housing casings, etc., improvement of strength and high temperature properties such as ignition resistance is crucial [10]. Addition of ceramic and metallic particulates as reinforcements is one of the methods to improve magnesium's property profile and performance, especially high temperature properties due to their thermal stabilities [11,12]. $\mathrm{B}_{4} \mathrm{C}$ nanoparticles were demonstrated to be promising as reinforcements owing to their role in improving the strengths of magnesium [13]. Boron carbide is the third hardest material known to man, after diamond and cubic boron nitride, and thus the addition of boron carbide would significantly influence the properties of magnesium, which is an inherently softer matrix. Further, addition of boron carbide to a matrix with secondary phases would change the distribution of secondary phases. This is because of the difference in the sizes of the nanoparticles and the secondary phases leading to an inhomogeneity in the processing of the materials [14]. Hence, this work is aimed at understanding the influence of boron carbide on the property profile of the E21 magnesium alloy.

\section{Materials and Methods}

\subsection{Primary Processing}

E21 alloy and E21- ${ }_{4} \mathrm{C}$ (1.5 and $\left.2.5 \mathrm{wt} . \%\right)$ nanocomposites were synthesized utilizing disintegrated melt deposition technique (DMD) [15]. E21 alloy procured in the form of chunks from Luxfer MEL Technologies (formerly known as Magnesium Elektron) and $\mathrm{B}_{4} \mathrm{C}$ nanoparticles of $\sim 50 \mathrm{~nm}$ size procured from Nabond, Hong Kong, were added in sandwich fashion and superheated to $750{ }^{\circ} \mathrm{C}$, under an inert argon gas atmosphere, within a graphite crucible using a resistance heating furnace. The crucible was equipped with a plug and nozzle for bottom pouring. Upon reaching the temperature $\left(750^{\circ} \mathrm{C}\right)$, the melt was stirred at $450 \mathrm{rpm}$ for 5 min utilizing a stirrer coated with ZIRTEX 25 to avoid iron contamination. After stirring, the plug of the crucible was pulled, and the molten metal was down poured into the mold. Before entering the mold, the molten metal was disintegrated by two jets of argon gas, with a flow rate maintained at $25 \mathrm{lpm}$. Following solidification, an ingot of $40 \mathrm{~mm}$ diameter was obtained. Three materials were cast in total: (i) Elektron 21 alloy; (ii) Elektron 21 with $\mathrm{B}_{4} \mathrm{C}$ nanoparticles of approximately $50 \mathrm{~nm}$ added at $1.5 \mathrm{wt} . \%$; and (iii) $2.5 \mathrm{wt} . \%$, respectively, using this method. The composition of the final materials is given in Table 1 .

Table 1. Nominal elemental composition of the materials in the study supplied by Luxfer MEL Technologies.

\begin{tabular}{ccccccc}
\hline Material (wt.) & Nd & Gd & Zn & Zr & B4C & Mg \\
\hline E21 Alloy & 2.8 & 1.4 & 0.3 & 0.5 & - & Bal. \\
E21-1.5B4C Nanocomposite & 2.8 & 1.4 & 0.3 & 0.5 & 1.5 & Bal. \\
E21-2.5B4C Nanocomposite & 2.8 & 1.4 & 0.3 & 0.5 & 2.5 & Bal. \\
\hline
\end{tabular}




\subsection{Secondary Processing}

The ingots were machined to billets with a length of $50 \mathrm{~mm}$ before they were sent to the extrusion process. The billets were soaked for an hour at $450{ }^{\circ} \mathrm{C}$ and extruded at $400{ }^{\circ} \mathrm{C}$ at a $20.25: 1$ extrusion ratio to obtain rods of $8 \mathrm{~mm}$ diameter.

\subsection{Testing and Characterization}

\subsubsection{Density and Porosity Measurements}

Using the rule of mixtures, the theoretical densities of the synthesized $\mathrm{Mg}$ materials were calculated [16]. Experimental densities of the materials were calculated using the gas pycnometer. The samples were placed in the gas pycnometer and sealed. Helium gas was then released into the chamber to measure the samples' experimental density. The porosity of the samples was calculated using the theoretical and experimental densities, under the presumption that the differential value arising between the theoretical and experimental densities is due to the porosity entrapped in the materials. The formula used to calculate the porosity is given below:

$$
P=\frac{\left(\rho_{\text {th }}-\rho_{e}\right)}{\left(\rho_{\text {th }}-\rho_{\text {air }}\right)} \times 100,
$$

where $P$ represents the porosity (in\%), $\rho$ represents density $(\mathrm{g} / \mathrm{cc})$, 'th' represents theoretical, and 'e' represents experimental.

\subsubsection{Microstructural Characterization}

The samples were ground and polished to remove any deformations or scratches on their surfaces, and etched to reveal grain boundaries. The etchant used for these materials was a solution containing $20 \mathrm{~mL}$ of acetic acid, $1 \mathrm{~mL}$ of $\mathrm{HNO}_{3}, 60 \mathrm{~mL}$ of ethylene glycol, and $20 \mathrm{~mL}$ of water. An optical microscope Leica DM2500 M was used to observe the grain characteristics. After the images were obtained, MATLAB software was used to calculate the average grain size of the materials. Further, the presence and distribution of the intermetallic phases and nanoparticles were studied using a JEOL JSM-6010PLUS/LV Scanning Electron Microscope (SEM), Peabody, MA, USA. Elemental analysis was performed using energy dispersion spectroscopy (EDS).

\subsubsection{X-Ray Diffraction Studies}

The XRD studies were conducted on the longitudinal section of the extruded samples using an automated Shimadzu lab-X XRD-6000 diffractometer (Kyoto, Japan). The samples were exposed to $\mathrm{Cu} \mathrm{K} \alpha$ radiation of wavelength $\lambda=1.5418 \AA$ with a scan speed of $2^{\circ} / \mathrm{min}$ and a scanning range of $20^{\circ}$ to $65^{\circ}$. The bragg angles, intensity peaks, and the values of the interplanar spacing, $\mathrm{d}$, obtained were subsequently matched with the standard values of $\mathrm{Mg}, \mathrm{Zr}, \mathrm{Gd}, \mathrm{Nd}, \mathrm{Zn}, \mathrm{B}_{4} \mathrm{C}$, and related phases. Furthermore, the basal plane orientation of Mg-based rare earth alloys was analyzed from the XRD peaks obtained at $2 \theta=34^{\circ}$.

\subsubsection{Damping Capacity and Young's Modulus}

Samples of $7.5 \mathrm{~mm}$ diameter and $60 \mathrm{~mm}$ length were subjected to impulse excitation to measure their damping characteristics (Damping Capacity, Loss Rate, Frequency and Young's modulus). The vibrational damping capacity of the materials was determined by using the response frequency damping analyzer (RFDA) from IMCE Belgium. The vibration signal was recorded in terms of amplitude vs. time. The attenuation coefficient was calculated with the help of GetData graph digitizer software, which allowed for a qualitative analysis of the damping capacity of the material. 


\subsubsection{Compression Testing}

The compressive tests were carried out in accordance with ASTM test method E9-09 on the MTS 810 testing machine at ambient temperature, using a strain rate of $0.01 \mathrm{~min}^{-1}$.

The samples with a length to diameter ratio of 1.5 were machined from the extruded rods with a diameter of $7 \mathrm{~mm}$. Key mechanical properties such as $0.2 \%$ offset yield strength $(0.2 \% \mathrm{YS})$, ultimate compressive strength (UCS), failure strain (FS), and energy absorbed (EA) were extracted from the graphs. A minimum of 5 tests were conducted to ensure repeatability.

\subsubsection{Ignition Temperature Determination}

The ignition temperatures of the materials were determined using a Thermo Gravimetric Analyzer (TGA). Samples of dimensions $2 \times 2 \times 1 \mathrm{~mm}^{3}$ were placed in purified air with a flow rate of $50 \mathrm{~mL} / \mathrm{min}$. They were heated from 30 to $1000^{\circ} \mathrm{C}$ at a heating rate of $10^{\circ} \mathrm{C} / \mathrm{min}$. The ignition temperature was recorded at a point where there was a rapid increase in the mass of the sample due to sharp oxidation upon ignition. The temperature rate was restored to the set-value after the sample burnt out. The crucible was taken out immediately after the test to prevent overflow of the oxidized power from the sample and contamination of TGA.

\section{Results and Discussion}

\subsection{Structural Characterization}

The addition of nanoparticles changes the density of the materials. The results of density and porosity measurements of as-extruded E21 magnesium alloy and E21- $\mathrm{B}_{4} \mathrm{C}(1.5 \%$ and $2.5 \%)$ magnesium nanocomposites are shown in Figure 1. It is observed that with the addition of denser $\mathrm{B}_{4} \mathrm{C}$ (density: $2.52 \mathrm{~g} / \mathrm{cc}$ ) to E21 alloy (density: $1.8 \mathrm{~g} / \mathrm{cc}$ ), the density of the E21 alloy increases. However, since the density of boron carbide is low compared to other ceramic nanoparticles, the overall density is maintained to be less than $1.81 \mathrm{~g} / \mathrm{cc}$ for the nanocomposites, which is far less than aluminum-based bulk materials and only $4 \%$ higher than that of pure $\mathrm{Mg}$. It can also be seen from the Figure 1 that the porosity (\%) of the nanocomposites is higher than that of the alloy. However, since all the materials exhibited porosity less than $0.6 \%$, it is implied that near dense materials have been fabricated using the DMD casting technique and the effects of porosity on the properties of the alloy and nanocomposites can be considered negligible.

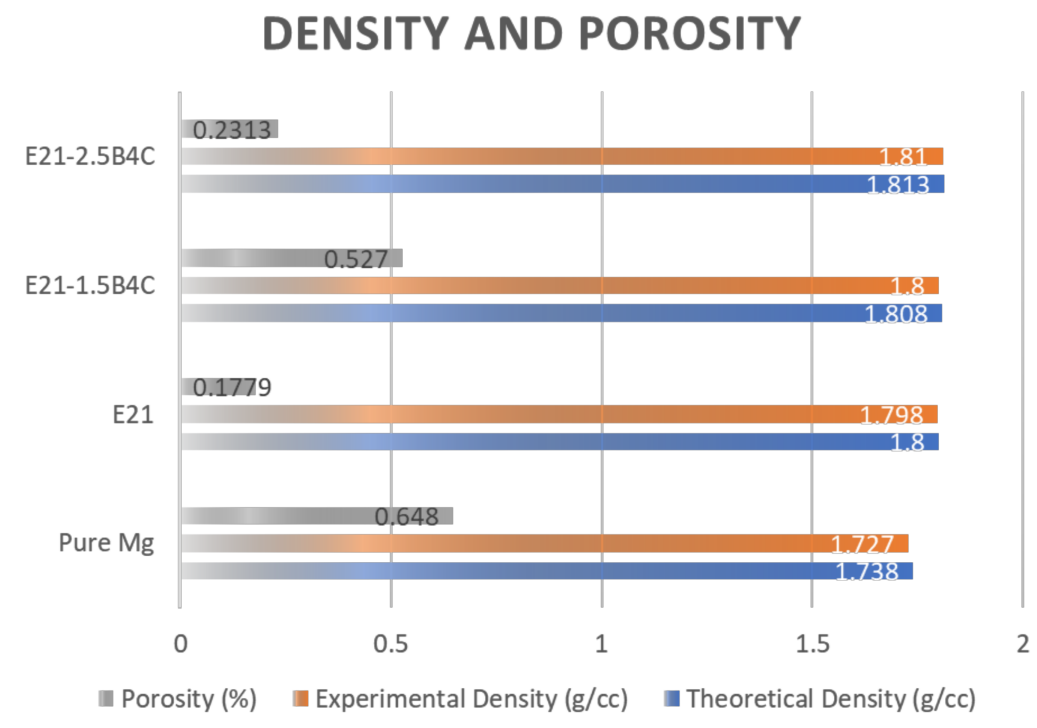

Figure 1. Density and porosity results of the as-extruded materials studied in this work. 
The addition of $\mathrm{B}_{4} \mathrm{C}$ nanoparticles to the $\mathrm{E} 21$ alloy disturbs the microstructural homogeneity of the alloy. This is because, in conjunction to the change in density, the intrinsic structure of the nanocomposites differs in terms of the grain characteristics, secondary phase distribution, and nanoparticle dispersion as compared to that of the alloy. Figure 2a-c shows the grain characteristics of the alloy and nanocomposites. Based on visual inspection and careful image analysis and quantification, it is estimated that the mean grain sizes of the nanocomposites were smaller than that of the E21 alloy. The average grain sizes of the materials are given in the insets in Figure 2, with E21 alloy exhibiting the highest average grain size. The average grain sizes are $29 \%$ and $27 \%$ lower in $E 21-B_{4} C$ and $E 21-2.5 B_{4} C$ nanocomposites, respectively, compared to that of the parent material E21 alloy. Further, an interesting observation is that the difference in grain size between the two nanocomposites is very minimal.

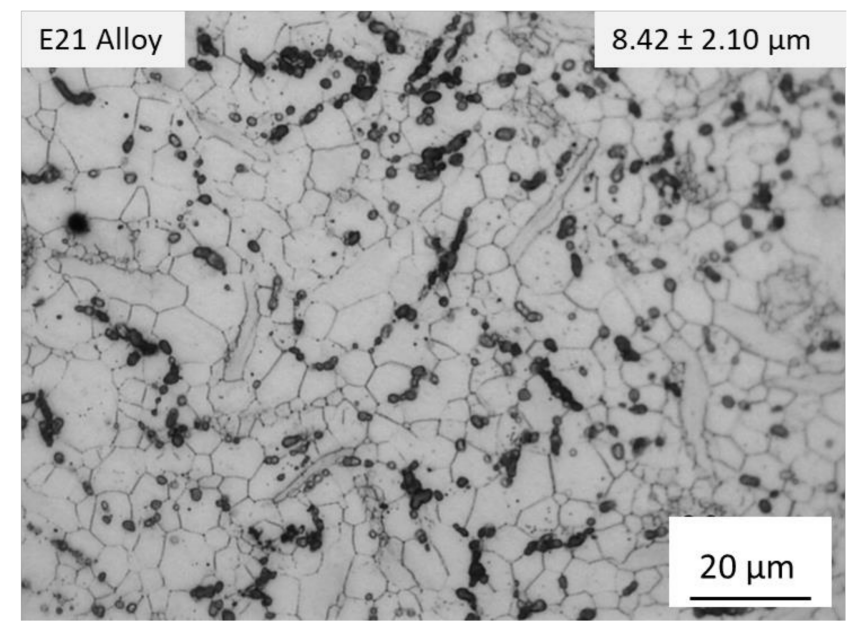

(a)

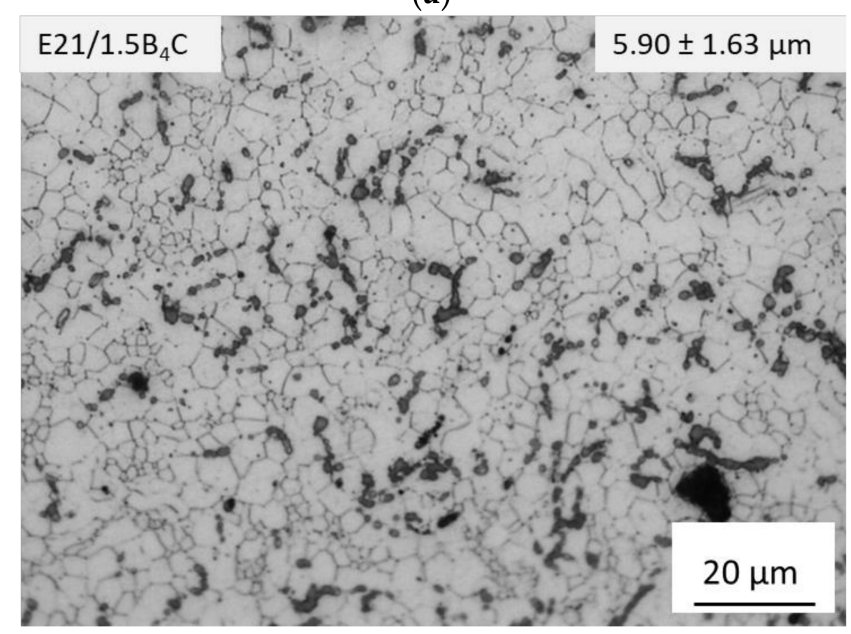

(b)

Figure 2. Cont. 


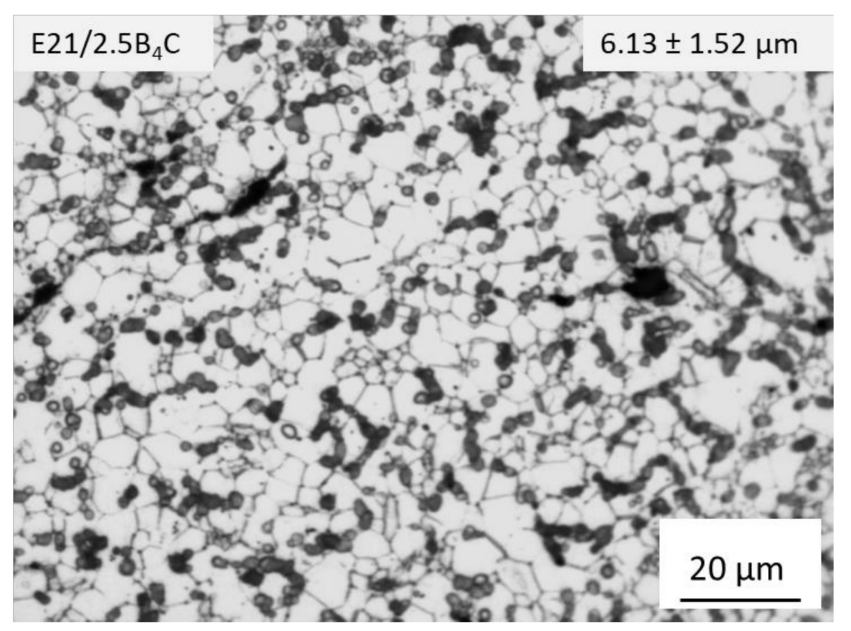

(c)

Figure 2. Optical micrographs of (a) E21 alloy; (b) E21-1.5B ${ }_{4} \mathrm{C}$ nanocomposite; and (c) E21-2.5B 4 C nanocomposites. The average grain sizes are given in the insets in the images.

Apart from the grain sizes, other significant changes in the microstructure with the incorporation of $\mathrm{B}_{4} \mathrm{C}$ nanoparticles are the distribution of secondary phases and nanoparticles. Secondary phases of Mg-RE (Mg-Nd and Mg-Nd-Gd) and Zr-rich phases are seen in the SEM image of the E21 alloy, as given in Figure 3a and as confirmed by EDS point analysis. Zinc is found to be dissolved in the matrix owing to its good solid solubility in $\mathrm{Mg}$. From Figure 2 it is evident that the secondary phases are found predominantly at the grain boundaries. With the addition of $\mathrm{B}_{4} \mathrm{C}$ nanoparticles, apart from the previously discussed $\mathrm{Mg}$ - $\mathrm{RE}$ phases and $\mathrm{Zr}$ phases, the presence of $\mathrm{B}_{4} \mathrm{C}$ particles were also observed. Although, the presence of $\mathrm{B}_{4} \mathrm{C}$ nanoparticles cannot be assertively confirmed by SEM + EDS, due to the limitation of the EDS to detect elements with lower atomic numbers [17], a few boron carbide nanoparticles were identified based on the EDS point analysis as seen in Figure 3b. Based on Figure $3 b$, it is observed that the nanoparticles are found in the matrix. However, due to the large volume fraction of the secondary phases, the nanoparticles can also segregate towards the secondary phases [18]; however, this needs further confirmation with the use of high resolution TEM. Further, XRD was used to confirm the presence of $\mathrm{B}_{4} \mathrm{C}$ nanoparticles as well as to identify the type of secondary phases. From the XRD spectra in Figure $3 c$, the presence of $\mathrm{B}_{4} \mathrm{C}$ is evident in the nanocomposites with peaks corresponding to $\mathrm{B}_{4} \mathrm{C}$ at $26^{\circ}$ diffraction angles. In addition, the intensity of this peak is seen to increase from $\mathrm{E} 21-1.5 \mathrm{~B}_{4} \mathrm{C}$ to $\mathrm{E} 21-2.5 \mathrm{~B}_{4} \mathrm{C}$ due to the increased content of $\mathrm{B}_{4} \mathrm{C}$ particles. Further, $X R D$ results also confirmed the presence of the phases $M_{3} R E$ and $M_{41} R E_{5}$, which correspond to $\mathrm{Mg}_{3} \mathrm{Nd} / \mathrm{Gd}$ and $\mathrm{Mg}_{41} \mathrm{Nd}_{5} / \mathrm{Gd}_{5}$, respectively. $\mathrm{Zn}$ and $\mathrm{Zr}$ were not detected by $\mathrm{XRD}$, as $\mathrm{Zn}$ is thought to be dissolved in magnesium, while $\mathrm{Zr}$ 's percentage in Elektron 21 is too little and, hence, it is difficult for the filtered X-ray to detect the phase when the volume percentage of the phase present in the alloys is less than $2 \%[19]$.

Thus, from the microstructural analysis, a few distinct observations can be made: (i) $\mathrm{Zn}$ is present as part of the solid solution of magnesium matrix; (ii) distinct secondary phases of $\mathrm{Mg}-\mathrm{Nd}$ and $\mathrm{Mg}-\mathrm{Gd}$ are seen in the matrix and the different secondary phases seem to co-exist; (iii) Zr particles are seen in the Mg matrix; (iv) Mg-Nd phase had the highest concentration amongst all the other phases owing to the higher concentration of $\mathrm{Nd}$ in the E21 alloy [20]; (v) $\mathrm{B}_{4} \mathrm{C}$ nanoparticles are present in the matrix and the nanoparticles aided the secondary phases in the grain refinement of the material due to the observation of grain refinement in the nanocomposites with the aid of nanoparticles. 

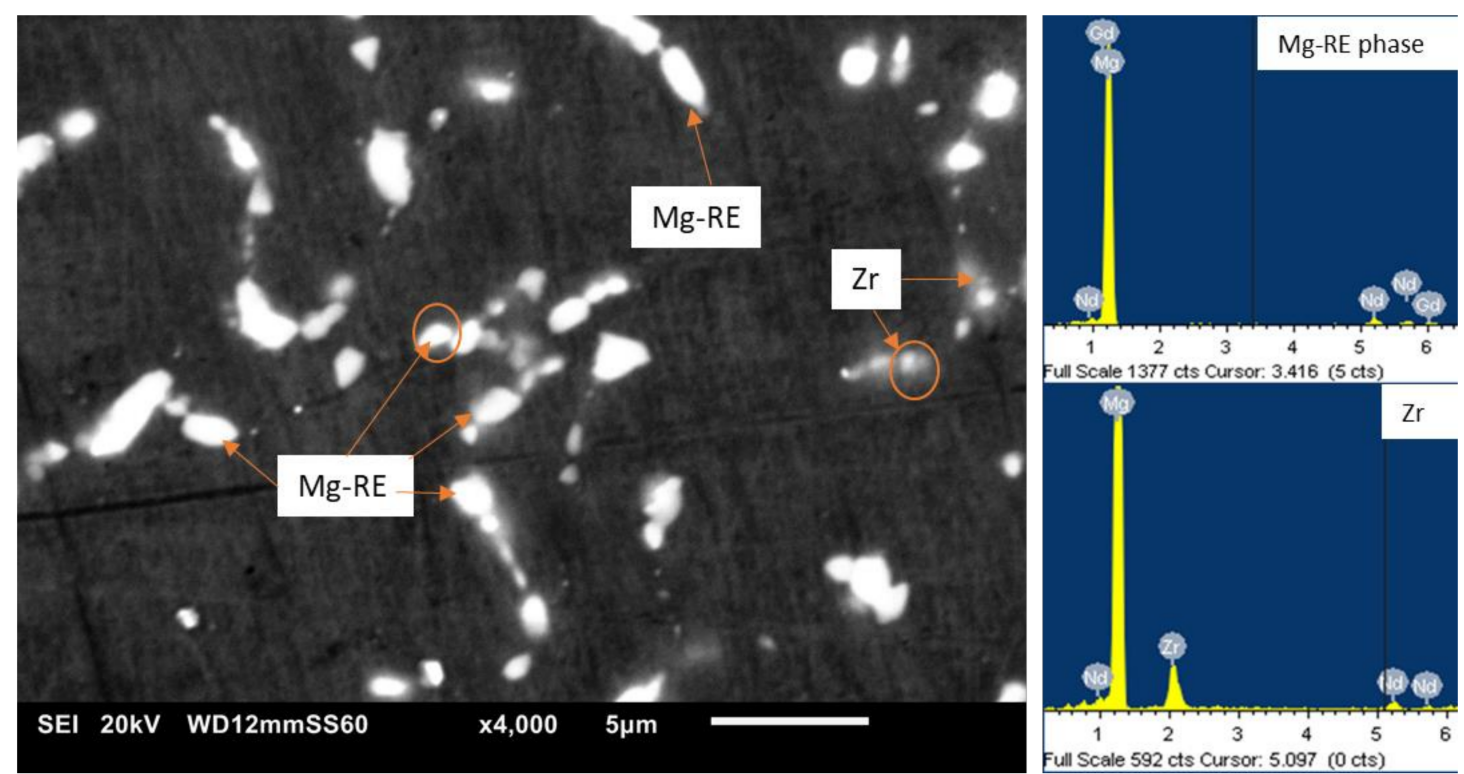

(a)
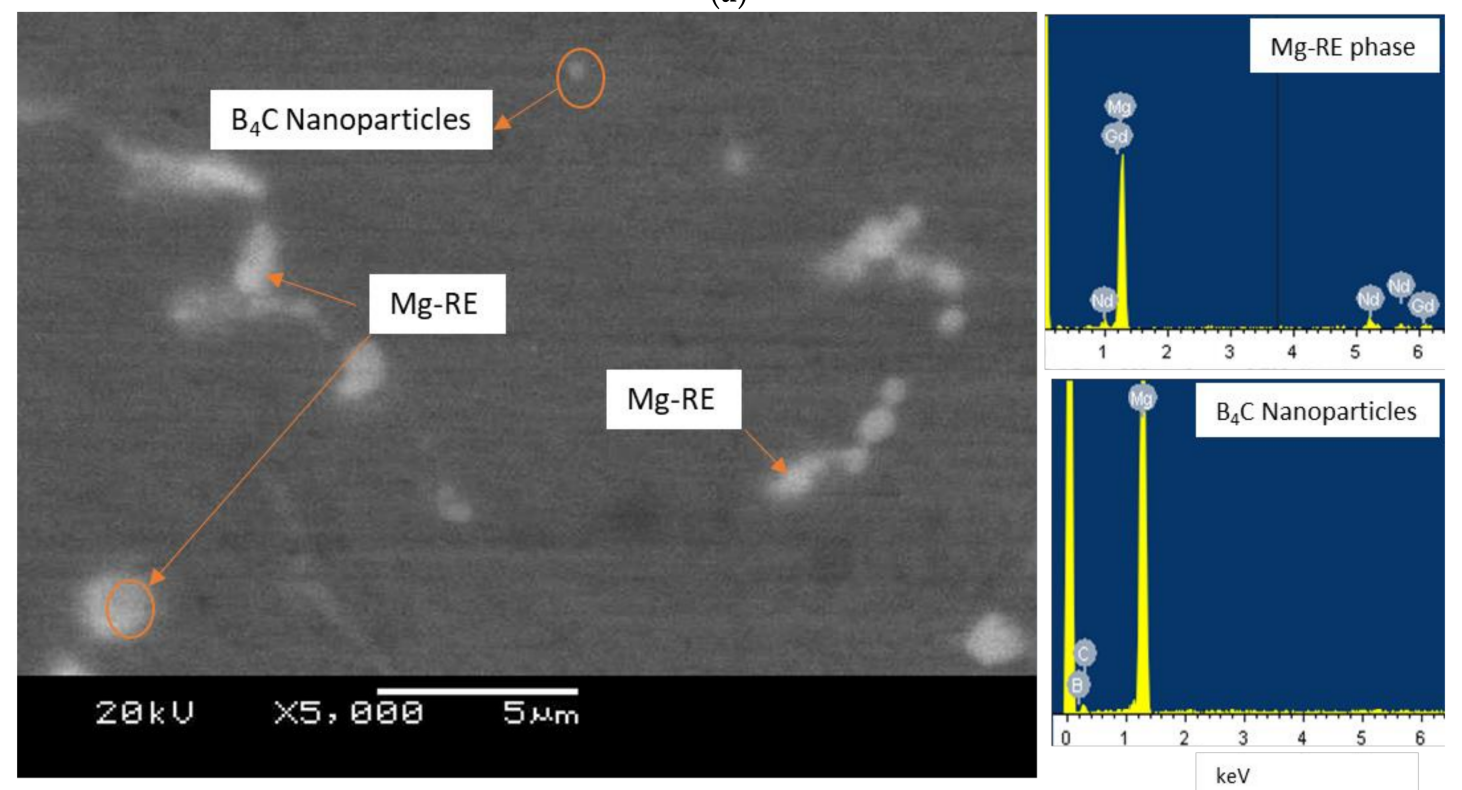

(b)

Figure 3. Cont. 


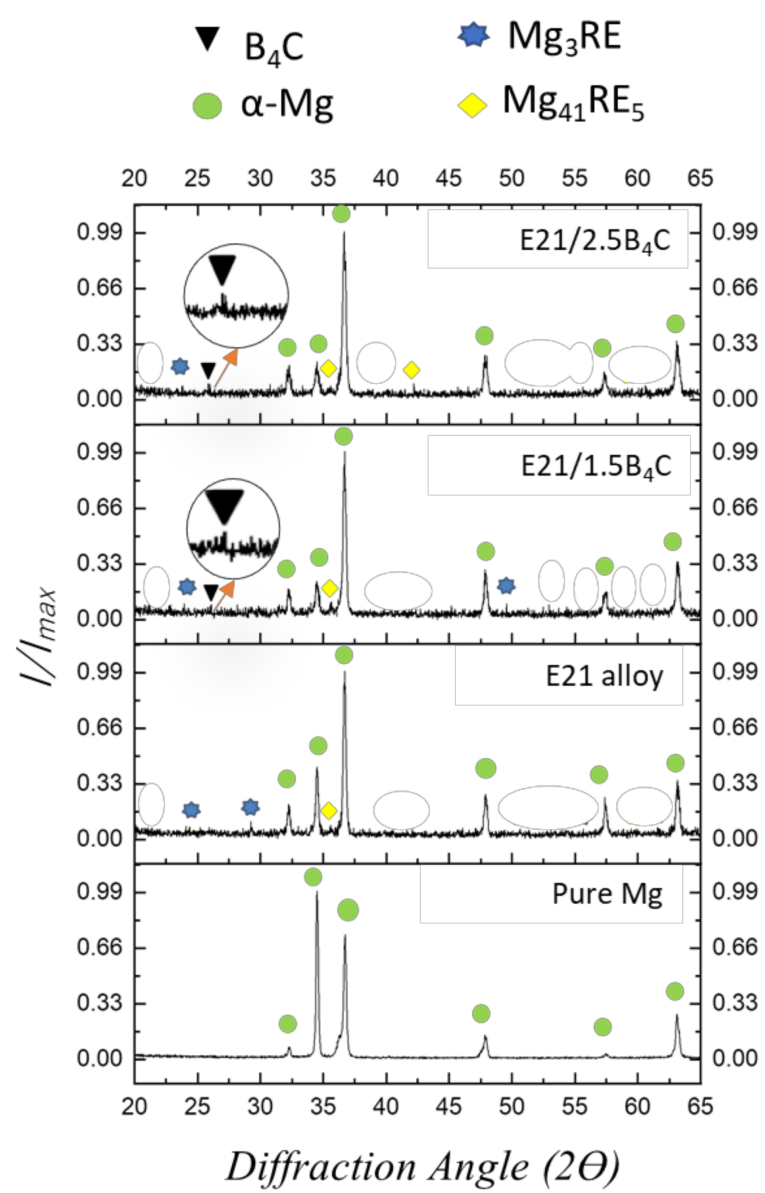

(c)

Figure 3. Scanning electron micrographs with energy dispersive spectroscopy (EDS) analysis of (a) E21 alloy; (b) microstructure of E21-1.5B $\mathrm{B}_{4} \mathrm{C}$ nanocomposite with EDS point analysis of boron carbide nanoparticle and Mg-RE (Mg-Nd-Gd) phase; and (c) X-ray diffraction spectra of the materials taken on the longitudinal section of the samples.

From the microstructural analysis of secondary phases, nanoparticles, and grain sizes, the results confirm that the nanoparticles contributed to the further grain refining of the material. This is in contrary to the previously reported alloy nanocomposites, where marginal grain coarsening was observed when nanoparticles were added to magnesium-based alloys [14,21]. In previous works, it was reported that the nanoparticles, in certain magnesium matrices, alter the mechanism of dynamic recrystallization, from Zener pinning to localized particle stimulated nucleation, causing an inhomogeneity and; therefore, a bimodal grain size across the nanocomposite [14]. However, in this case, the nanoparticles aided the secondary phases in pinning the grain boundaries and refine the grains. It is proposed that this could be due to the segregation of the secondary phases at the liquid- $\mathrm{B}_{4} \mathrm{C}$ nanoparticle interface [22], thereby leading to the secondary phase and nanoparticles complementing each other in the process of grain refinement.

\subsection{Property Profile}

\subsubsection{Mechanical Properties}

The compressive results of the developed Mg alloys are shown in Figure 4, where the representative engineering stress-strain curves of the E21 alloy and its nanocomposites under compression are depicted. E21 alloy is known for its good mechanical properties exhibiting a good strength and moderate ductility. 


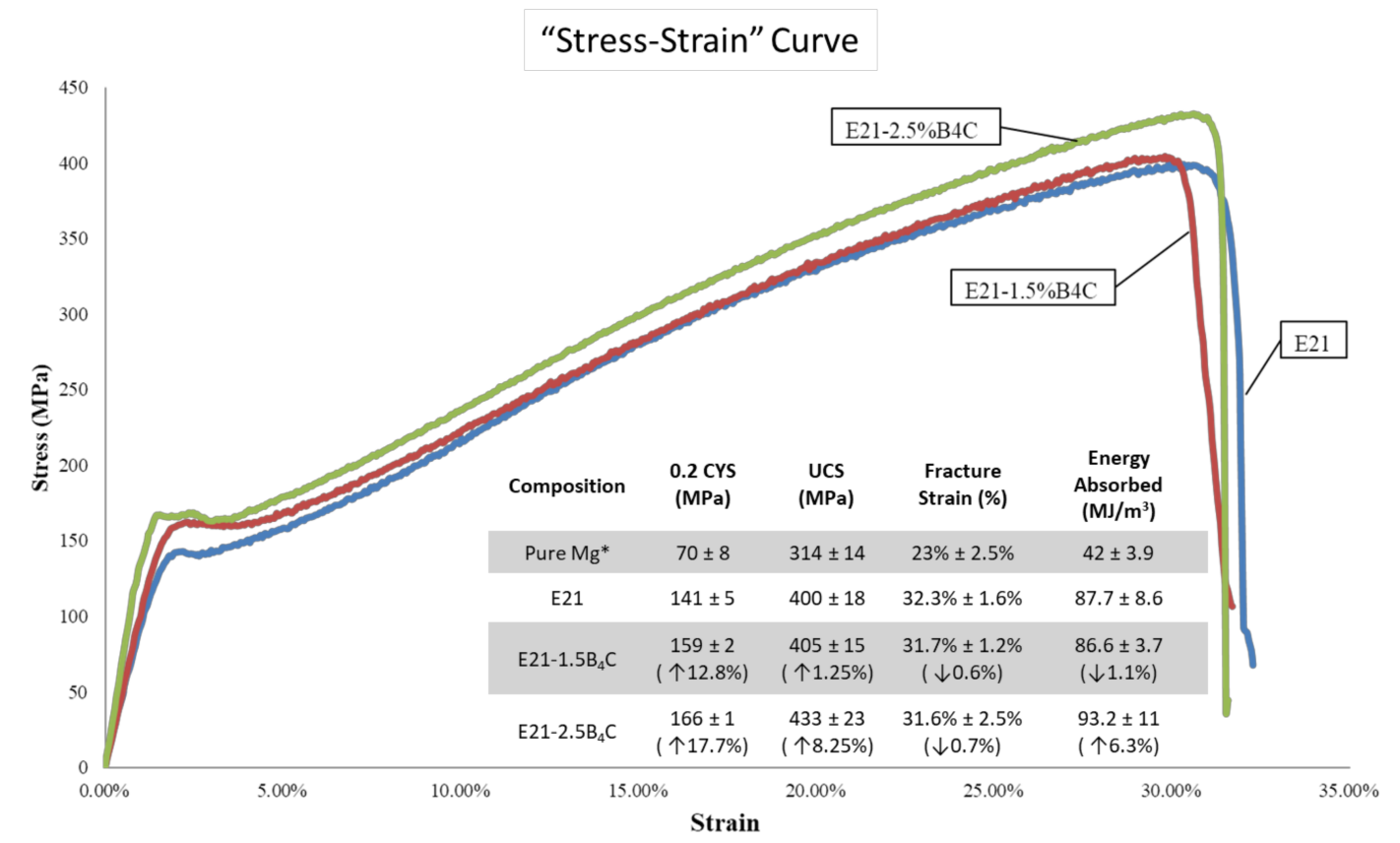

(a)

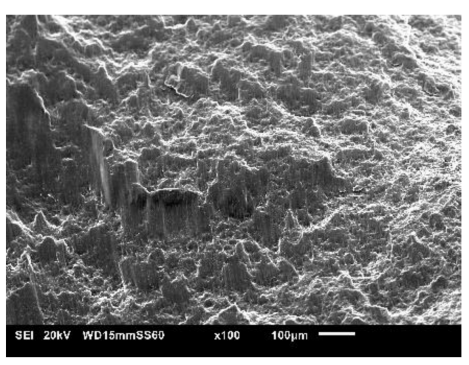

(b)

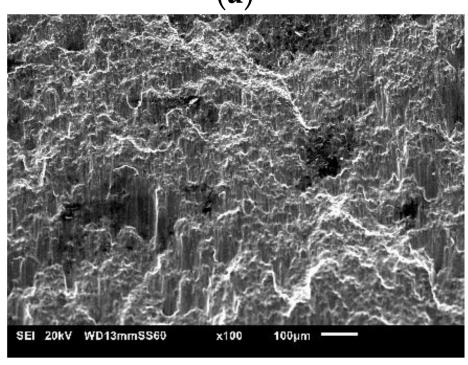

(c)

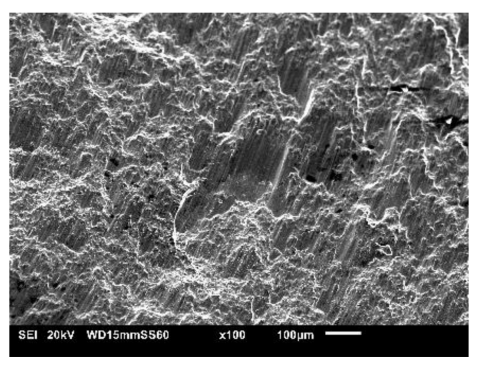

(d)

Figure 4. (a) Engineering stress-strain curves of all materials tested under uniaxial compressive loading; (b) fractography of the Elektron21 (E21) sample fractured under compression; (c) fractography of E21-1.5B ${ }_{4} \mathrm{C}$ sample fractured under compression; and (d) fractograph of E21-2.5B ${ }_{4} \mathrm{C}$ sample fractured under compression.

From Figure 4, it is noticeable that the E21- $\mathrm{B}_{4} \mathrm{C}$ nanocomposites outperform the E21 alloy in the compressive yield strengths while maintaining the same strain to failure. The YS and UCS of E21-1.5 $\mathrm{B}_{4} \mathrm{C}$ increases by $12.8 \%$ and $1.25 \%$, respectively, with respect to the E21 alloy, while the YS and UCS of E21-2.5B ${ }_{4} \mathrm{C}$ increases by $17.7 \%$ and $8.25 \%$, respectively, with the E21 alloy. Further, the total energy absorbed values are seen to be the highest in $\mathrm{E} 21-2.5 \mathrm{~B}_{4} \mathrm{C}$ with $6.3 \%$, as compared to that of the E21 alloy.

It is widely known that, at most low-temperatures, permanent deformation of metal comes from the movement of crystalline imperfections, known as dislocations, through the grains in the metal [23]. The addition of boron carbide nanoparticles reduced the grain sizes in E21 alloy; a change in grain size affects the yield strength due to the dislocations interacting with the grain boundary as they move. These boundaries act as obstacles, hindering the dislocation glide along the slip planes. As subsequent dislocations move along the same slip plane, the dislocations pile-up at the grain boundaries. On the contrary, a larger grain would result in more dislocations within the grain, resulting in more dislocations in the pile-up. Therefore, a lower applied stress is required to produce a stress great enough to cause the grain boundary to collapse. Furthermore, due to the presence of higher volume fraction of nanoparticles present in $\mathrm{E} 21-2.5 \mathrm{~B}_{4} \mathrm{C}$, the contribution to strengthening by boron carbide nanoparticles is significant compared to E21 and E21-1.5B ${ }_{4} \mathrm{C}$. In addition, the further increase in YS and UCS in 
E21-2.5B $\mathrm{B}_{4} \mathrm{C}$ could also be due to the increased dislocation density formed due to coefficient of thermal expansion mismatch between reinforcements and matrix. This creates an excellent improvement in strength while maintaining the ductility, which makes it a viable option to be used in the aerospace sector. The samples had a very large strain-to-failure of greater than $30 \%$ and the same is observed in the fractographs given in Figure $4 \mathrm{~b}-\mathrm{d}$. From the figures, it is confirmed that the amount of plastic deformation underwent by all the materials is very high and the samples typically deformed by shear. Further, there is no significant difference in the mode of deformation observed among the materials which reinforces the fact that the nanoparticles did not hamper the compressive ductility in the nanocomposites.

\subsubsection{Damping Capacity and Young's Modulus}

Damping capacity of the materials is presented in Figure 5 in terms of time and amplitude of the material and Table 2 with results from the resonance frequency damping analyzer (RFDA).

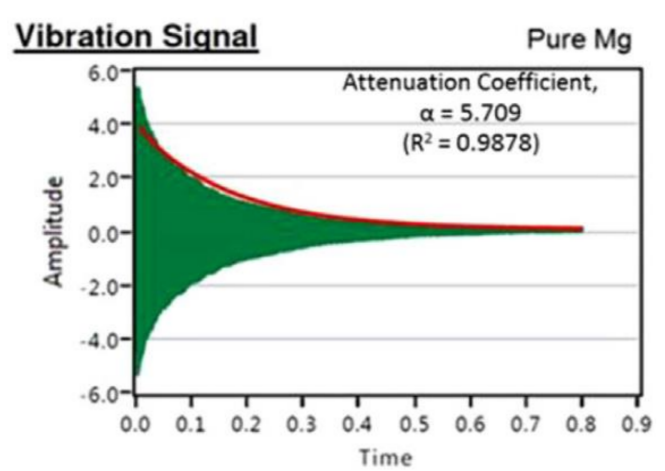

(a)

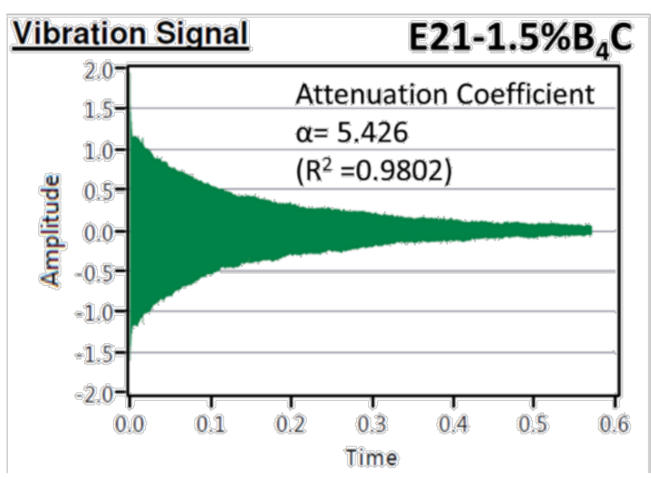

(c)

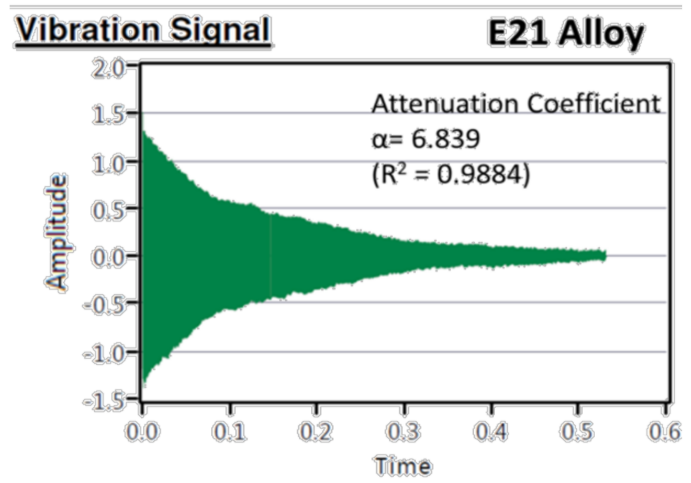

(b)

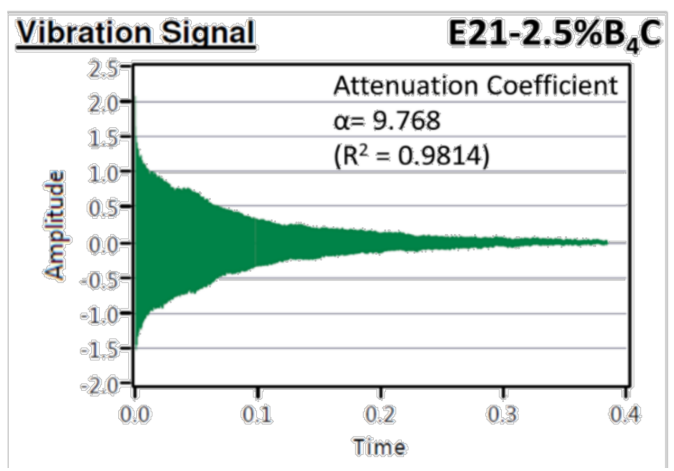

(d)

Figure 5. Damping characteristics of (a) Pure Mg; (b) Elektron 21 (E21) alloy; (c) E21-1.5B $\mathrm{B}_{4} \mathrm{C}$ nanocomposite; and (d) E21-2.5B $\mathrm{B}_{4} \mathrm{C}$ nanocomposite given in terms of amplitude vs. time.

Table 2. Results of the Resonance Frequency Damping Analyzer.

\begin{tabular}{ccccc}
\hline Composition & Frequency (Hz) & Loss Rate (\%) & Damping Capacity & Young's Modulus (GPa) \\
\hline E21 Alloy & 8760.58 & 6.2 & 0.000225 & 48.14 \\
E21-1.5B ${ }_{4}$ C Nanocomposite & 8332.76 & 5.6 & 0.000213 & 47.18 \\
E21-2.5B $_{4}$ C Nanocomposite & 8361.67 & 10.8 & 0.000413 & 52.02 \\
\hline
\end{tabular}

The table above shows the results of frequency, damping capacity, loss rate, and Young's modulus of each composition. The damping capacity and Young's modulus are not observed to change in E21-1.5 $\mathrm{B}_{4} \mathrm{C}$ magnesium alloy but increase significantly in E21-2.5B $\mathrm{B}_{4} \mathrm{C}$ magnesium alloy. The amplitude of vibration against time for each composition can be seen in the Figure 5. The time taken for each composition to stop vibration is the qualitative measurement of the damping capacity. Among the 
three compositions, $\mathrm{E} 21-2.5 \mathrm{~B}_{4} \mathrm{C}$ takes the least time ( $\left.0.38 \mathrm{~s}\right)$ to stop the vibration, which is far less than the time required by pure $\mathrm{Mg}$ to stop the vibration ( $\sim 0.8 \mathrm{~s})$. Currently, most of the currently used metallic materials exhibit low-damping capacity and, hence, special energy absorbers and dampeners are necessary to be incorporated into the dynamic structures [24]. This is taken more seriously in the aerospace sector, where the vibrations in the aircraft during flight can be extremely high [25]. Therefore, a large damping capacity is desirable for materials used in structures where unwanted vibrations are induced during operation, such as machine tool bases or crankshafts; especially in the aerospace sector, to reduce the chance of a crack in the components of the aircraft. This makes E21-2.5 wt. $\% \mathrm{~B}_{4} \mathrm{C}$ a very suitable material, as it offers an excellent damping capacity.

Young's Modulus can also be seen to increase to as high as $52 \mathrm{GPa}$ in E21-2.5B $\mathrm{B}_{4} \mathrm{C}$. With a higher Young's modulus, the material is deemed more desirable in structural aerospace components in service for a longer duration, and works as a better replacement for other commercially used magnesium-based materials in applications requiring high stiffness.

\subsubsection{Ignition Properties}

The results of ignition temperature testing are shown in the schematic in Figure 6. The ignition temperature increases with the addition of $\mathrm{B}_{4} \mathrm{C}$ nanoparticles. There is a sharp increase in ignition temperature from $\mathrm{E} 21-1.5 \mathrm{~B}_{4} \mathrm{C}$ to $\mathrm{E} 21-2.5 \mathrm{~B}_{4} \mathrm{C}$. A maximum ignition temperature of $798^{\circ} \mathrm{C}$ was observed in $\mathrm{E} 21-2.5 \mathrm{~B}_{4} \mathrm{C}$ and the ignition temperature increased by about $57^{\circ} \mathrm{C}(7.7 \%)$ in the nanocomposite, which indicates the effectiveness of $\mathrm{B}_{4} \mathrm{C}$ particles in enhancing the ignition properties of magnesium.

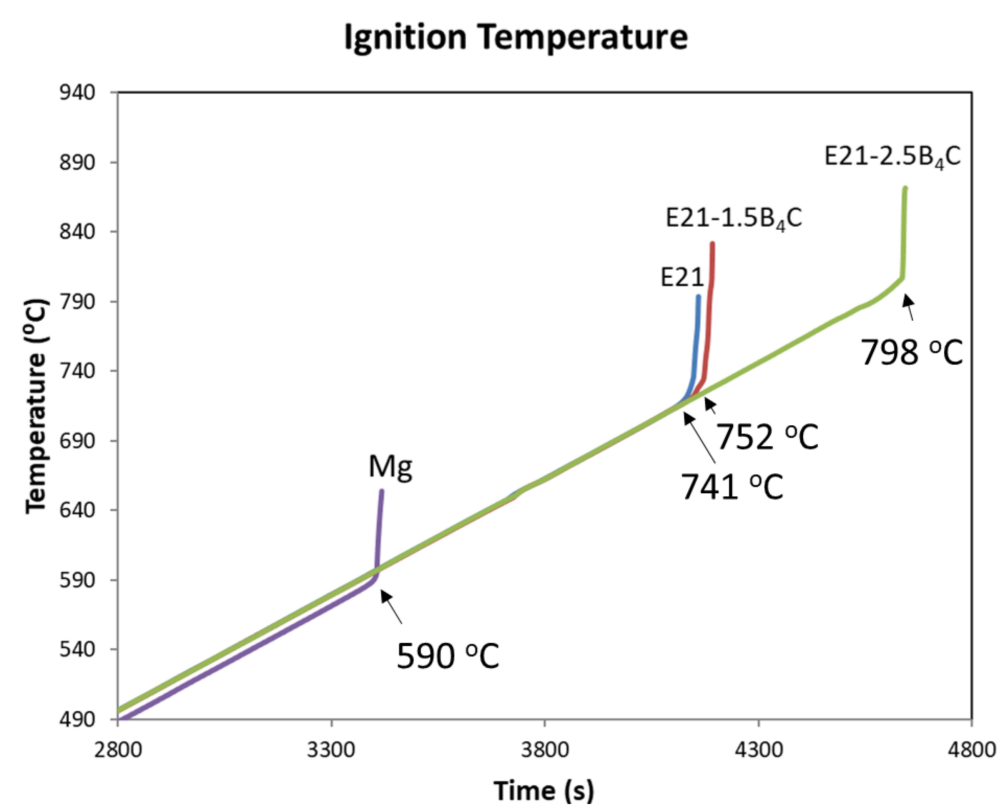

(a)

Figure 6. Cont. 


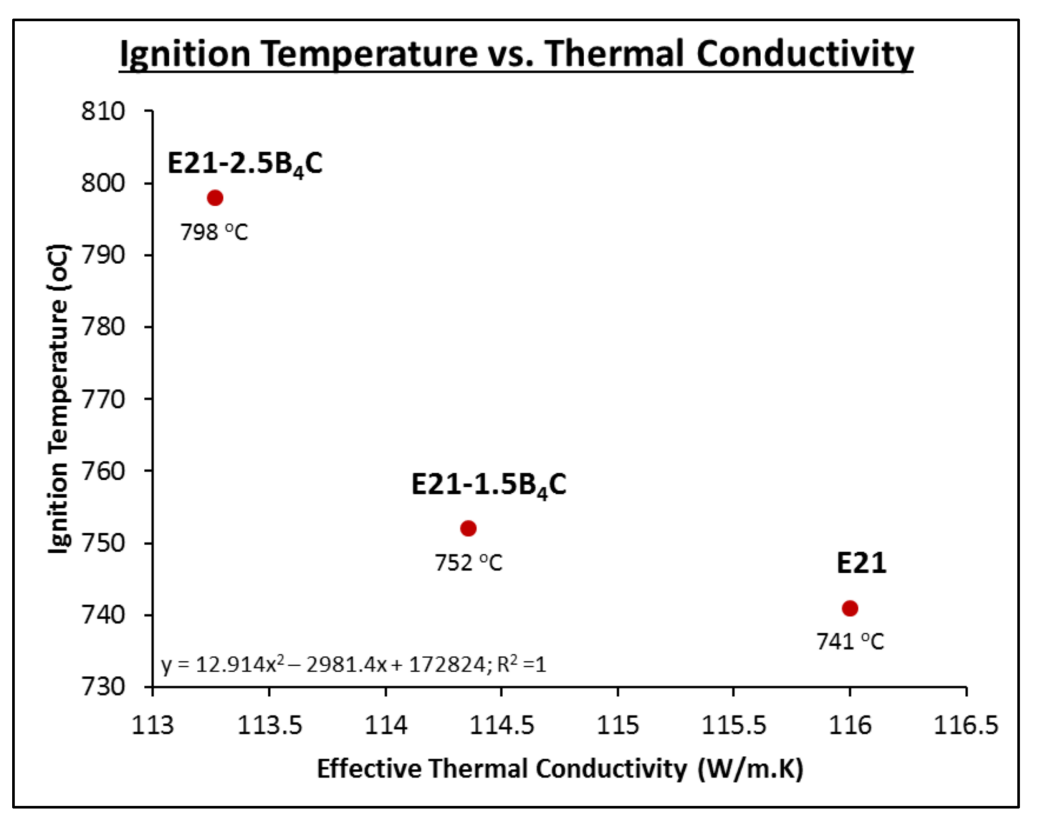

(b)

Figure 6. (a) Thermo-gravimetric analysis of materials to determine their ignition temperatures; and (b) ignition temperature vs. effective thermal conductivity of the materials following a polynomial fit. It is to be noted that the effective thermal conductivity is calculated using the rule of mixtures.

E21 alloy has a high ignition temperature with delayed flammability and, hence, is approved by FAA to be used in in-cabin applications [5]. This is due to the presence of a class of elements which have a positive influence on enhancing the ignition temperature. Rare earths like $\mathrm{Nd}$ and $\mathrm{Gd}$ are found in E21, raising magnesium's ignition temperature from 590 to $741^{\circ} \mathrm{C}$, as shown in Figure 6 [10]. Further, Figure $6 \mathrm{a}$ demonstrates that ignition temperature increases with the addition of $\mathrm{B}_{4} \mathrm{C}$ nanoparticles. There is a sharp spike in ignition temperature from $\mathrm{E} 21-1.5 \mathrm{~B}_{4} \mathrm{C}$ to $\mathrm{E} 21-2.5 \mathrm{~B}_{4} \mathrm{C}$; due to the additional $1 \% \mathrm{~B}_{4} \mathrm{C}$ added in the nanocomposite. $\mathrm{B}_{4} \mathrm{C}$ has excellent thermal properties, with a high specific heat capacity, low thermal conductivity, and a low thermal coefficient of expansion; it brings about thermal stability to E21. Figure $6 \mathrm{~b}$ gives the relation between the thermal conductivity of the material and the ignition temperature and it has always been observed that the ignition temperature is higher for materials with lower thermal conductivity. Therefore, it is probable that the increased weight fraction of $\mathrm{B}_{4} \mathrm{C}$ nanoparticles in $\mathrm{E} 21-2.5 \mathrm{~B}_{4} \mathrm{C}$ can bring about a higher ignition temperature as it is more thermally stable as compared to the other compositions. This is essential, as it is an improvement in the thermal and ignition properties of E21 alloy, one of the few magnesium-based alloys to meet the survivability model of the Federal Aviation Administration, allowing E21 to be more reliant and suitable in the aerospace industry.

E21-2.5B $\mathrm{B}_{4} \mathrm{C}$ is an example of a nanocomposite, another emerging class of materials with extremely good mechanical properties coupled with thermal integrity owing to the presence of dimensionally stable ceramic or metallic reinforcements, which provide high mechanical strength as well as ignition resistance.

\section{Conclusions}

E21 has good overall properties, being one of the only few magnesium-based materials to meet the FAA's survivability requirements; good chemical resistance due to the tight control of $\mathrm{Zn}$ content; good mechanical, physical, and ignition properties due to the addition of $\mathrm{Nd}, \mathrm{Gd}$, and $\mathrm{Zr}$. In this investigation, the effects of $\mathrm{B}_{4} \mathrm{C}$ in E21 alloy were studied with the goal of further improving the properties of E21 alloy to be used in a wider range of applications in the aerospace sector. From the results and analysis, the following conclusions can be drawn: 
(1) The presence of $\mathrm{B}_{4} \mathrm{C}$ nanoparticles in E21 alloy did not significantly increase the density of nanocomposites but reduced the grain sizes of E21 alloy by $29 \%$.

(2) The mechanical strength (i.e., compressive yield strength and ultimate strength of the nanocomposites, particularly $\mathrm{E} 21-2.5 \mathrm{~B}_{4} \mathrm{C}$ ) increased significantly without compromising on ductility.

(3) The damping capacity of $\mathrm{E} 21-2 \cdot 5 \mathrm{~B}_{4} \mathrm{C}$ is the highest, with the fastest time taken to stop the vibration. This makes $\mathrm{E} 21-2.5 \mathrm{~B}_{4} \mathrm{C}$ a promising material to be used in the aerospace sector without the need for any special energy absorbers.

(4) The addition of $\mathrm{B}_{4} \mathrm{C}$ nanoparticles in E21 alloys also led to the promising behavior of E21 alloy in terms of their ignition response. E21-2.5B $\mathrm{B}_{4} \mathrm{C}$ demonstrated the highest ignition temperature of $798^{\circ} \mathrm{C}$, which is about $57^{\circ} \mathrm{C}$ higher than the E21 alloy, showcasing the positive role of boron carbide nanoparticles.

(5) Thus, E21-2.5 $\mathrm{B}_{4} \mathrm{C}$ nanocomposites with boron carbide nanoparticles areca desirable and suitable material for the aerospace industry to be used in in-cabin applications, as well as for gearbox housing applications.

Author Contributions: Conceptualization and design of experiments, S.T. and M.G.; performed the experiments and analyzed the data, S.T. and N.J.Y.; material selection and ideation, S.T., M.H. and M.G.; writing-original draft preparation, S.T.; writing-review and editing, S.T. and M.G.; project administration, S.T.; funding acquisition, M.G.

Funding: This research was funded by Singapore Ministry of Education (MOE) Tier 2, grant number R265-000-622-112.

Acknowledgments: The authors thank Jurami Bin Madon for his assistance with extrusion and Ng Hong Wei for his assistance with experiments on TGA.

Conflicts of Interest: The authors declare no conflict of interest. The funders had no role in the design of the study; in the collection, analyses, or interpretation of data; in the writing of the manuscript, or in the decision to publish the results.

\section{References}

1. Safehaven.com. New Tech Could Transform the $\$ 2$ Trillion Auto Industry. Available online: https://www. prnewswire.com/news-releases/new-tech-could-transform-the-2-trillion-auto-industry-673561583.html (accessed on 19 August 2019).

2. Arnaldo Valdés, R.M.; Burmaoglu, S.; Tucci, V.; Braga da Costa Campos, L.M.; Mattera, L.; Gomez Comendador, V.F. Flight path 2050 and acare goals for maintaining and extending industrial leadership in aviation: A map of the aviation technology space. Sustainability 2019, 11, 2065. [CrossRef]

3. Perera, F. Pollution from fossil-fuel combustion is the leading environmental threat to global pediatric health and equity: Solutions exist. Int. J. Environ. Res. Public Health 2017, 15, 16. [CrossRef] [PubMed]

4. Czerwinski, F. Controlling the ignition and flammability of magnesium for aerospace applications. Corros. Sci. 2014, 86, 1-16. [CrossRef]

5. Marker, T.R. Development of a Laboratory Scale Flammability Test for Magnesium Alloys used in Aircraft Seat Construction; Federal Aviation Administration Technical Center: New Jersey, NJ, USA, 2014.

6. Lu, Y.; Bradshaw, A.R.; Chiu, Y.L.; Jones, I.P. Effects of secondary phase and grain size on the corrosion of biodegradable mg-zn-ca alloys. Mater. Sci. Eng. C 2015, 48, 480-486. [CrossRef] [PubMed]

7. Yang, W.; Tekumalla, S.; Gupta, M. Cumulative effect of strength enhancer-Lanthanum and ductility enhancer-Cerium on mechanical response of magnesium. Metals 2017, 7, 241. [CrossRef]

8. Saboori, A.; Padovano, E.; Pavese, M.; Badini, C. Novel magnesium elektron21-aln nanocomposites produced by ultrasound-assisted casting; microstructure, thermal and electrical conductivity. Materials (Basel) 2017, 11, 27. [CrossRef] [PubMed]

9. Tekumalla, S.; Seetharaman, S.; Almajid, A.; Gupta, M. Mechanical properties of magnesium-rare earth alloy systems: A review. Metals 2015, 5, 1-39. [CrossRef]

10. Tekumalla, S.; Gupta, M. An insight into ignition factors and mechanisms of magnesium based materials: A review. Mater. Des. 2017, 113, 84-98. [CrossRef] 
11. Tekumalla, S.; Nandigam, Y.; Bibhanshu, N.; Rajashekara, S.; Yang, C.; Suwas, S.; Gupta, M. A strong and deformable in-situ magnesium nanocomposite igniting above $1000{ }^{\circ} \mathrm{C}$. Sci. Rep. 2018, 8, 7038. [CrossRef] [PubMed]

12. Chen, Y.; Tekumalla, S.; Guo, Y.B.; Gupta, M. Introducing mg-4zn-3gd-1ca/zno nanocomposite with compressive strengths matching/exceeding that of mild steel. Sci. Rep. 2016, 6, 32395. [CrossRef] [PubMed]

13. Sankaranarayanan, S.; Sabat, R.K.; Jayalakshmi, S.; Suwas, S.; Gupta, M. Effect of nanoscale boron carbide particle addition on the microstructural evolution and mechanical response of pure magnesium. Mater. Des. (1980-2015) 2014, 56, 428-436. [CrossRef]

14. Tekumalla, S.; Bibhanshu, N.; Suwas, S.; Gupta, M. Superior ductility in magnesium alloy-based nanocomposites: The crucial role of texture induced by nanoparticles. J. Mater. Sci. 2019, 54, 8711-8718. [CrossRef]

15. Gupta, M.; Wong, W.L.E. Magnesium-based nanocomposites: Lightweight materials of the future. Mater. Charact. 2015, 105, 30-46. [CrossRef]

16. Chawla, K.K. Composite Materials: Science and Engineering; Springer: New York, NY, USA, 2012.

17. Berlin, J. Analysis of boron with energy dispersive x-ray spectrometry. Imaging Microsc. 2011, 13, $19-21$.

18. Chen, Y.; Tekumalla, S.; Guo, Y.B.; Shabadi, R.; Shim, V.P.W.; Gupta, M. The dynamic compressive response of a high-strength magnesium alloy and its nanocomposite. Mater. Sci. Eng. A 2017, 702, 65-72. [CrossRef]

19. Cullity, B.D. Elements of X Ray Diffraction-Scholar's Choice Edition; Scholar's Choice: Wolcott, NY, USA, 2015.

20. Kiełbus, A.; Rzychoń, T.; Lityńska-Dobrzyńska, L.; Dercz, G. Characterization of $\beta$ and mg41nd5 equilibrium phases in elektron 21 magnesium alloy after long-term annealing. Solid State Phenom. 2010, 163, 106-109. [CrossRef]

21. Tekumalla, S.; Farhan, N.; Srivatsan, T.S.; Gupta, M. Nano-zno particles' effect in improving the mechanical response of mg-3al-0.4ce alloy. Metals 2016, 6, 276. [CrossRef]

22. Nie, K.; Zhu, Z.; Deng, K.; Wang, T.; Han, J. Hot deformation behavior and processing maps of sic nanoparticles and second phase synergistically reinforced magnesium matrix composites. Nanomaterials (Basel) 2019, 9, 57. [CrossRef] [PubMed]

23. Tekumalla, S.; Shabadi, R.; Yang, C.; Seetharaman, S.; Gupta, M. Strengthening due to the in-situ evolution of B1' mg-zn rich phase in a zno nanoparticles introduced mg-y alloy. Scr. Mater. 2017, 133, 29-32. [CrossRef]

24. Li, B.; Lavernia, E.J. 3.23-spray forming of mmcs. In Comprehensive Composite Materials; Kelly, A., Zweben, C., Eds.; Pergamon: Oxford, UK, 2000; pp. 617-653.

25. Bai, J.; Wang, C.; Wan, F.; Yan, G. Review of aircraft vibration environment prediction methods. Procedia Environ. Sci. 2011, 10, 831-836. [CrossRef] 